\title{
A Cross-Sectional Concept Elicitation Study to Understand the Impact of Herpes Zoster on Patients' Health-Related Quality of Life
}

\author{
Desirée Van Oorschot · Ashleigh McGirr · Philibert Goulet • \\ Patricia Koochaki · Ramya Pratiwadi · Selam Shah · Desmond Curran
}

Received: June 28, 2021 / Accepted: December 6, 2021 / Published online: January 7, 2022

(C) The Author(s) 2022

\begin{abstract}
Introduction: After a chickenpox infection, the varicella zoster virus lies dormant in nerve cells and can be reactivated in later life to cause herpes zoster (HZ), also called shingles, a painful rash that may result in persistent postherpetic neuralgia (PHN). Treatment options are limited, and HZ/PHN may have substantial negative effects on health-related quality of life (HRQoL). This qualitative cross-sectional study explored the subjective patient experience and impact on HRQOL of $\mathrm{HZ}$ and PHN in adults aged $\geq 50$ years in Canada.
\end{abstract}

Methods: Patients were eligible for the study if they were aged at least 50 years and had been

Supplementary Information The online version contains supplementary material available at https:// doi.org/10.1007/s40121-021-00581-w.

D. Van Oorschot $(\varangle) \cdot$ P. Goulet · D. Curran

GSK, Wavre, Belgium

e-mail: desiree.x.van-oorschot@gsk.com

A. McGirr

GSK, Mississauga, Canada

P. Koochaki

Mapi Group, Health Research and

Commercialization ICON Plc, Cincinnati, OH, USA

R. Pratiwadi

ICON Plc, San Francisco, CA, USA

S. Shah

ICON Plc, Boston, MA, USA diagnosed with $\mathrm{HZ}$ by a healthcare practitioner 7-60 days earlier for HZ patients and 90-365 days earlier for PHN patients. Eligible patients were invited to participate in concept elicitation interviews by telephone. Data from the interviews were transcribed and analyzed to identify key concepts related to symptoms and impacts on the patients' lives.

Results: A total of 32 patients participated, with a mean age of 61 years. Most (72\%) were female. The most common symptoms reported were rash $(n=32)$, pain $(n=31)$, fatigue $(n=26)$, and itchiness $(n=20)$. The most commonly reported HRQoL domains affected were emotional functioning $(n=31)$, activities of daily living $(n=31)$, sleep $(n=29)$, physical functioning $(n=25)$ and hobbies $(n=21)$. A conceptual model was developed to summarize these symptoms and impacts.

Conclusion: HZ negatively affected many dimensions of patients' HRQoL, particularly during the acute phase of illness. This qualitative study helps to broaden understanding of the subjective patient experience of HZ. 


\section{Graphical Abstract:}

\section{Plain Language Summary}

\section{What is the context?}

- Herpes Zoster $(\mathrm{HZ})$ occurs due to the reactivation of the varicella zoster virus that lies dormant in nerve cells after a chickenpox infection.

- The most common complication of $\mathrm{HZ}$ is postherpetic neuralgia (PHN), persistent severe pain in the area of the $\mathrm{HZ}$ rash.

- $\mathrm{HZ}$ and PHN negatively affect physical, psychological, social and functional domains of quality of life (QoL).

- This qualitative study explored the impact of $\mathrm{HZ}$ and PHN on QoL in adults aged 50 years or more in Canada.

\section{What is new?}

- A total of 32 patients, with a mean age of 61 years and a majority of females, participated in concept elicitation interviews by telephone.

- This is the first qualitative exploration of QoL impact in $\mathrm{HZ}$ or PHN patients in Canada.

- The most common symptoms reported were rash, pain, fatigue, and itchiness.

- The results indicated that $\mathrm{HZ} / \mathrm{PHN}$ have impact on a wide range of aspects of QoL, such as emotional functioning, activities of daily living, sleep, physical functioning and hobbies.

- A conceptual model was developed to summarize these symptoms and impacts.

\section{What is the impact?}

- $\mathrm{HZ}$ negatively affected many dimensions of patients' QoL, particularly during the acute phase of illness.

- This qualitative study helps to broaden understanding of the patient experience of $\mathrm{HZ}$.

- The conceptual model should help heathcare professionals to develop a broader understanding of the impact of $\mathrm{HZ} / \mathrm{PHN}$ on patients' lives, so that they can support patients with healthcare interventions.

The graphical PLS represents the opinions of the authors. For a full list of declarations, including funding and author disclosure statements, please see the full text online. () The authors, CC-BY-NC 2021.

$\begin{array}{ll}\square \text { OPEN } & \begin{array}{l}\text { A cross-sectional concept elicitation study to understand } \\ \text { the impact of herpes zoster on patients' health-related } \\ \text { 2. ACCESS }\end{array} \\ \text { quality of life. Van Oorschot D, McGirr A, Goulet P, } \\ \text { Koochaki P, Pratiwadi R, Shah S, Curran D. }\end{array}$


Keywords: Postherpetic neuralgia; Qualitative research; Shingles

\section{Key Summary Points}

Why carry out this study?

The risk of herpes zoster (HZ) and postherpetic neuralgia ( $\mathrm{PHN}$ ), the most common complication (in 10-18\% of patients), increases with age.

This study explored the impact of $\mathrm{HZ}$ and PHN on the health-related quality of life of adults $\geq 50$ years old in Canada.

\section{What was learned from the study?}

$\mathrm{HZ}$ and PHN have a negative impact on the quality of life of patients, especially during the acute phase of the disease.

The conceptual model may help healthcare professionals better understand the subjective patient experience of $\mathrm{HZ}$ and PHN.

\section{INTRODUCTION}

Infection with the varicella zoster virus (VZV) initially causes chickenpox, typically in children. After a chickenpox infection, the virus can lie dormant in the nervous system for decades and can reactivate in later life as immune function declines. Virus reactivation causes herpes zoster (HZ), also called shingles, characterized by a painful localized rash [1]. Almost the entire adult population is infected by varicella zoster virus; approximately one-third of the population in the United States of America develop $\mathrm{HZ}$ at least once in a lifetime [2], and the lifetime risk of at least one VZV reactivation is estimated at $28 \%$ in Canada [3]. The most common complication of $\mathrm{HZ}$ is postherpetic neuralgia (PHN), persistent pain in the area of the $\mathrm{HZ}$ rash, which occurs in $10-18 \%$ of patients with $\mathrm{HZ}$ [2]. The risk of both $\mathrm{HZ}$ and PHN increases with advancing age, especially after the age of 50-60 years [1]. In Canada, the number of HZ cases is estimated at 130,000 each year, with 17,000 cases of PHN $[4,5]$.

Current treatment options for HZ are limited, and PHN is often refractory to treatment with half of patients reporting symptom relief [6]. Several quantitative studies using established patient-reported outcome (PRO) measures have shown that $\mathrm{HZ}$ and PHN negatively affect health-related quality of life (HRQoL). HZ and PHN negatively affect physical, psychological, social and functional domains of HRQoL measured using the Short Form-36 (SF-36), with an impact comparable to that of other chronic debilitating diseases such as congestive heart failure, clinical depression, diabetes mellitus and myocardial infarction [6]. In France all HRQoL scores on the SF-36 were reduced in patients with $\mathrm{HZ}$ or PHN compared with a French reference population [7], and in Germany $\mathrm{HZ}$ and PHN substantially reduced HRQoL scored using the EuroQoL five-dimension scale (EQ-5D) [8]. Greater acute pain in HZ was significantly associated with poorer physical, role and social functioning and more emotional distress [9], and increases in the intensity of pain/discomfort in $\mathrm{HZ}$ worsened $\mathrm{HRQOL}$ scores measured by the Short Form-12 (SF-12) and EQ-5D scales [10].

However, qualitative research on the subjective patient experience of $\mathrm{HZ}$ and $\mathrm{PHN}$ is limited. Concept elicitation studies using qualitative interviews can capture the patients' subjective experience of symptoms, the impact of illness on their daily lives and the language they choose to use to describe these symptoms and impacts [11]. Such qualitative research is used to identify the concepts that are important and relevant to patients and to evaluate the content validity of PRO measures [12, 13]. Concept elicitation interviews can help to develop a conceptual model to support a more complete understanding of the patient experience of illness [11, 14].

The objective of this study was to explore the impact of HZ on quality of life by conducting a qualitative assessment and developing a conceptual model of the impact of $\mathrm{HZ}$ and $\mathrm{PHN}$ on HRQoL in patients aged 50 years and older 
living in Canada, using concept elicitation interviews.

\section{METHODS}

\section{Defining the Concept Elicitation Framework}

A targeted literature review was conducted to identify previously conducted qualitative or quantitative research on the impacts of $\mathrm{HZ}$ and PHN on HRQoL in adult patients. Searches were performed in September and October 2018 in the PROLABELS database via ePROVIDE, in MEDLINE/Embase and PsycINFO via the OVID platform, and ClinicalTrial.gov, limited to human studies published in English. Studies were eligible for inclusion if they were: qualitative studies or clinical trials or observational studies using PRO reporting on symptoms, HRQoL and/or impacts; or patient preference or adherence studies that included relevant experience, symptom or impact data. Retrieved abstracts were screened by one reviewer and confirmed by another, and the most relevant, up-to-date and comprehensive studies were selected for full-text review. Concepts of symptoms and impacts on HRQoL reported in the selected literature were used to develop a draft conceptual model, which in turn was used to inform the development of a semi-structured interview guide for the concept elicitation interviews.

\section{Concept Elicitation Interviews}

Telephone interviews lasting up to $60 \mathrm{~min}$ each were conducted, aiming to identify key concepts relevant to patients with $\mathrm{HZ}$, including symptoms, impacts and overall HRQoL. Concept elicitation data were coded and analyzed in accordance with grounded theory analysis methods. Concepts emerging from participants, i.e. rather than imposing an a priori theory, were identified $[15,16]$. For each symptom reported, the interview explored aspects such as frequency, severity, duration, changes over time and impact on physical functioning, activities of daily living, sleep, social functioning and relationships, emotional functioning, work and career. Interviews were conducted by staff trained in qualitative research methods, using a semi-structured interview guide (Appendix S1) to allow patients to provide open-ended information about their experiences. Demographic information was collected at the start of the interview.

\section{Saturation Analysis}

The final sample size was based on reaching saturation within the groups, when further interviews no longer introduce new concepts or themes [16]. Previous research has suggested that $97 \%$ of symptom concepts emerge by the 20th interview [13]. Saturation was assessed using a documented codebook approach and saturation tables.

\section{Compliance with Ethics Guidelines}

All study materials were reviewed and approved by an independent ethics committee prior to patient recruitment [Advarra institutional review board (IRB), protocol number 0018-0873]. All interviewers received studyspecific training on the interview guide and study protocol. At the start of the telephone interview, patients were asked to verbally confirm their informed consent and permission for the interview to be recorded and transcribed. Patients received honoraria of 150 Canadian dollars (CAD) if they consented and took part in the interview and an additional CAD25 for providing confirmation of diagnosis. Such patient honoraria are permitted in Canada and were reviewed and approved by the local IRB.

\section{Eligibility Criteria and Patient Recruitment}

Patients were recruited through a healthcare patient recruitment agency, via support groups, proprietary databases, physician referrals and social media advertising using IRB-approved recruitment messages. Sampling was stratified by age and sex. Three groups of patients were 
recruited: Group A1, HZ patients interviewed 7-30 days after diagnosis; Group A2, HZ patients interviewed 31-60 days after diagnosis; and Group B, PHN patients. Groups A1 and A2 represent the acute phase of illness, and Group $B$ represents the post-acute phase.

Patients were eligible for inclusion in the study if they:

- had a clinical diagnosis of HZ. For HZ patients, the onset of pain must have been within 7-60 days after the initial HZ diagnosis. For PHN patients, they had to have zoster-related pain 90 days after the initial rash and 90-365 days after the initial HZ diagnosis;

- were aged 50 years or older, male or female;

- had English-speaking and comprehension levels sufficient to understand the research study, complete the study documents and participate in a telephone interview in English;

Patients were excluded if they had received a shingles vaccine in the past or if they could not comply with the study protocol. Any potential participants who met the eligibility criteria and were interested in participating were asked to provide confirmation of diagnosis either through a healthcare provider's confirmation or by providing a picture of their antiviral and/or $\mathrm{HZ}$ pain medication, and when confirmation was received they were invited to participate.

\section{Data Analysis}

Verbatim transcriptions of the interviews were analyzed using a thematic analysis approach [17]. Themes were identified by both topics and issues emerging directly from the data (inductive inference) and applying prior knowledge (abductive inference) [18]. This enables the analysis to remain firmly grounded in the data, facilitating the identification of concepts expressed by patients to identify areas important to them, while also considering work completed to date (i.e., evidence from the literature). All analysis was facilitated by qualitative analysis software (MAXQDA), which, combined with a codebook, enables a systematic approach to coding.

\section{RESULTS}

\section{Literature Review and Draft Conceptual Model}

The searches conducted via the Ovid platform identified 102 records for review, as summarized in Fig. S1 and Fig. S2, and a further 7 clinical trials were identified from the search of ClinicalTrial.gov.

The following themes and concepts were identified as important for the HRQoL of HZ patients (concepts are listed in parentheses after each theme):

- Disease management/attitude toward vaccination [e.g., poor knowledge of shingles and PHN (prevalence and severity)]

- Worries about vaccine side effects

- Work (e.g., fear of losing job because of sick leave)

- Physical functioning (e.g., fatigue, restlessness, etc.)

- Family functioning (e.g., importance of family support, change in family role, etc.)

- Activities of daily living (e.g., difficulty to find clothes or have bath, etc.)

- Emotional impact (e.g., depression, despair for pain relief, feeling becoming old, etc.)

- Social functioning (e.g., underestimation/ misunderstanding of shingles impact on life, etc.)

- Pain/pain management (e.g., difficulty in managing pain, dreadful pain, etc.)

The draft conceptual model constructed from these symptoms and HRQoL impact concepts is shown in Fig. S3.

\section{Patient Characteristics}

A total of 32 patients were interviewed for the study, $18 \mathrm{HZ}$ patients (Group A) and $14 \mathrm{PHN}$ patients (Group B). Among the HZ patients, eight patients were in Group A1, and ten were in Group A2. Patient characteristics are 


\section{Shingles}

\section{Can you tell me some words or phrases that come to mind that best describe what it's like to experience shingles?}

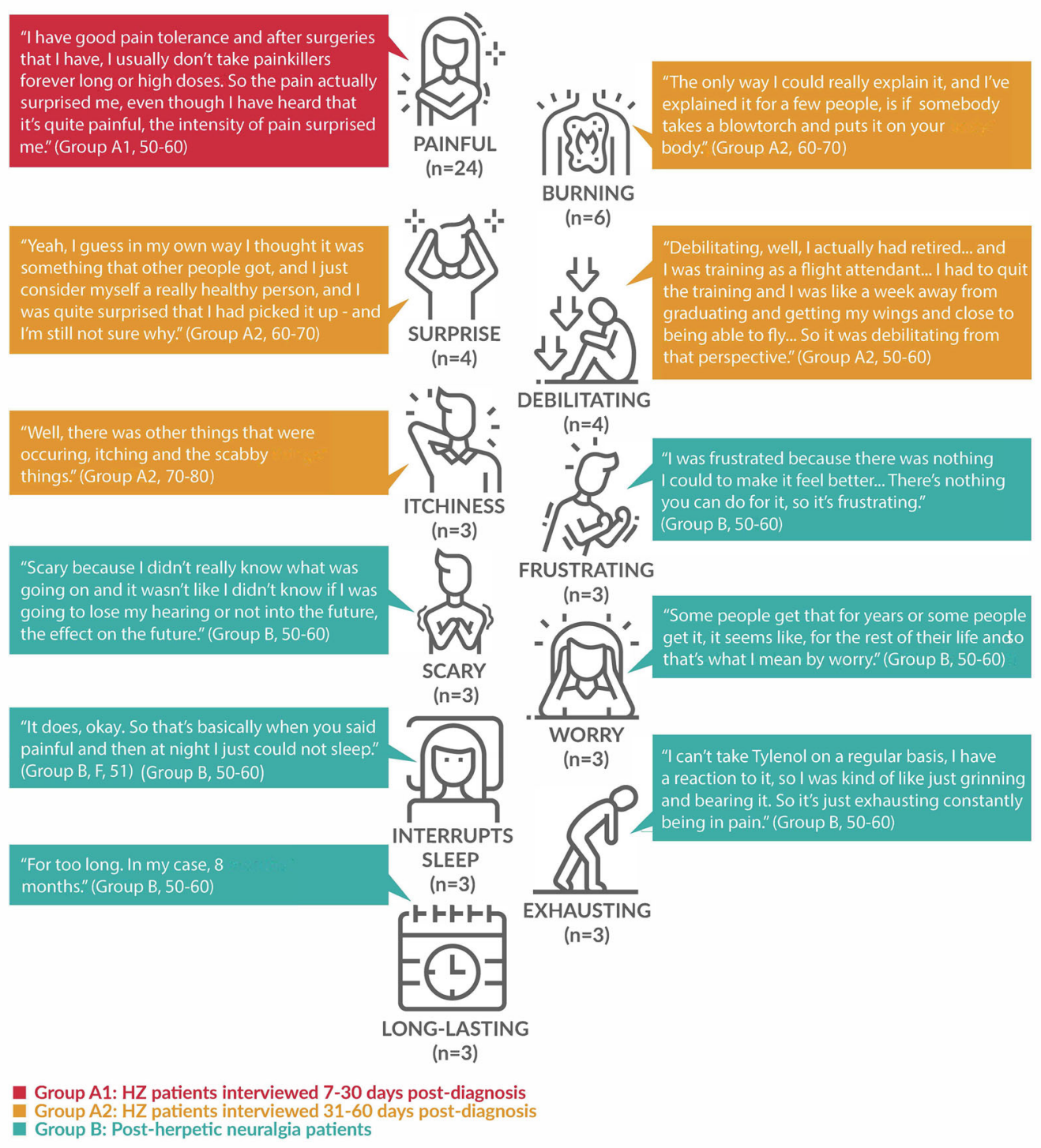

Fig. 1 Patient descriptions of HZ/PHN reported by at least three patients. $H Z$ herpes zoster, $P H N$ postherpetic neuralgia. Group A1, HZ 7-30 days post diagnosis; Group A2, HZ 31-60 days post diagnosis; Group B, PHN;

50-60, patients between 50 and 59 years of age; 60-70, patients between 60 and 69 years of age; $70-80$, patients between 70 and 79 years of age 
Table 1 Symptoms of HZ/PHN reported, by group

\begin{tabular}{|c|c|c|c|c|c|}
\hline Symptom & $\begin{array}{l}\text { Spontaneously } \\
\text { reported }\end{array}$ & $\begin{array}{l}\text { Reported } \\
\text { overall }\end{array}$ & $\begin{array}{l}\text { Reported as reason for } \\
\text { seeking diagnosis }^{\mathrm{a}}\end{array}$ & $\begin{array}{l}\text { Reported post- } \\
\text { acute phase }\end{array}$ & $\begin{array}{l}\text { Ranked as most } \\
\text { bothersome }\end{array}$ \\
\hline \multicolumn{6}{|c|}{ Group A1, HZ 7-30 days $(n=8)$} \\
\hline Rash & $8(100 \%)$ & $8(100 \%)$ & $8(100 \%)$ & - & $1(13 \%)$ \\
\hline Pain & $8(100 \%)$ & $8(100 \%)$ & $8(100 \%)$ & - & $5(63 \%)$ \\
\hline Fatigue & $7(88 \%)$ & $7(88 \%)$ & $1(20 \%)$ & - & - \\
\hline $\begin{array}{l}\text { Itchiness/ } \\
\text { dryness }\end{array}$ & $6(75 \%)$ & $6(75 \%)$ & $1(13 \%)$ & - & $2(25 \%)$ \\
\hline Headaches & $5(63 \%)$ & $5(63 \%)$ & $3(38 \%)$ & - & $1(13 \%)$ \\
\hline Tingling & $2(25 \%)$ & $2(25 \%)$ & $2(25 \%)$ & - & - \\
\hline Pinching & $2(25 \%)$ & $2(25 \%)$ & $1(13 \%)$ & - & - \\
\hline Fever & $1(13 \%)$ & $1(13 \%)$ & $1(13 \%)$ & - & - \\
\hline Muscle spasms & $1(13 \%)$ & $1(13 \%)$ & $1(13 \%)$ & - & - \\
\hline $\begin{array}{l}\text { Numbness and } \\
\text { tingling }\end{array}$ & $1(13 \%)$ & $1(13 \%)$ & - & - & - \\
\hline Swelling & $1(13 \%)$ & $1(13 \%)$ & - & - & - \\
\hline \multicolumn{6}{|c|}{ Group A2, HZ 31-60 days $(n=10)$} \\
\hline Rash & $10(100 \%)$ & $10(100 \%)$ & $10(100 \%)$ & - & $2(20 \%)$ \\
\hline Pain & $8(80 \%)$ & $9(90 \%)$ & $9(90 \%)$ & - & $7(70 \%)$ \\
\hline Fatigue & $9(90 \%)$ & $9(90 \%)$ & $2(20 \%)$ & - & - \\
\hline $\begin{array}{l}\text { Itchiness/ } \\
\text { dryness }\end{array}$ & $6(60 \%)$ & $6(60 \%)$ & $6(60 \%)$ & - & $2(20 \%)$ \\
\hline $\begin{array}{l}\text { Numbness and } \\
\text { tingling }\end{array}$ & $2(20 \%)$ & $2(20 \%)$ & - & - & - \\
\hline Headaches & $2(20 \%)$ & $2(20 \%)$ & $1(10 \%)$ & - & - \\
\hline $\begin{array}{l}\text { Lack of } \\
\text { sensation }\end{array}$ & $2(20 \%)$ & $2(20 \%)$ & - & - & - \\
\hline $\begin{array}{l}\text { Vision } \\
\text { problems }\end{array}$ & $2(20 \%)$ & $2(20 \%)$ & - & - & $1(10 \%)$ \\
\hline Fever & $2(20 \%)$ & $2(20 \%)$ & $2(20 \%)$ & - & - \\
\hline Eye irritation & $1(10 \%)$ & $1(10 \%)$ & $1(10 \%)$ & - & $1(10 \%)$ \\
\hline Tingling & $1(10 \%)$ & $1(10 \%)$ & $1(10 \%)$ & - & - \\
\hline Chills & $1(10 \%)$ & $1(10 \%)$ & $1(10 \%)$ & - & - \\
\hline Muscle aches & $1(10 \%)$ & $1(10 \%)$ & - & - & - \\
\hline Tenderness & $1(7 \%)$ & $1(7 \%)$ & - & - & - \\
\hline
\end{tabular}


Table 1 continued

\begin{tabular}{|c|c|c|c|c|c|}
\hline Symptom & $\begin{array}{l}\text { Spontaneously } \\
\text { reported }\end{array}$ & $\begin{array}{l}\text { Reported } \\
\text { overall }\end{array}$ & $\begin{array}{l}\text { Reported as reason for } \\
\text { seeking diagnosis }^{\mathrm{a}}\end{array}$ & $\begin{array}{l}\text { Reported post- } \\
\text { acute phase }\end{array}$ & $\begin{array}{l}\text { Ranked as most } \\
\text { bothersome }\end{array}$ \\
\hline \multicolumn{6}{|c|}{ Group B, PHN $(n=14)$} \\
\hline Rash & $14(100 \%)$ & $14(100 \%)$ & $14(100 \%)$ & $5(36 \%)$ & $1(7 \%)$ \\
\hline Pain & $14(100 \%)$ & $14(100 \%)$ & $14(100 \%)$ & $7(50 \%)$ & $9(64 \%)$ \\
\hline Fatigue & $8(57 \%)$ & $10(71 \%)$ & $3(21 \%)$ & $6(43 \%)$ & $1(7 \%)$ \\
\hline $\begin{array}{l}\text { Itchiness/ } \\
\text { dryness }\end{array}$ & $7(50 \%)$ & $8(57 \%)$ & $4(29 \%)$ & $3(21 \%)$ & $3(21 \%)$ \\
\hline Headaches & $3(21 \%)$ & $3(21 \%)$ & $2(14 \%)$ & $1(7 \%)$ & $2(14 \%)$ \\
\hline Tenderness & $3(21 \%)$ & $4(29 \%)$ & - & $4(29 \%)$ & - \\
\hline $\begin{array}{l}\text { Numbness and } \\
\text { tingling }\end{array}$ & $3(21 \%)$ & $3(21 \%)$ & - & $3(21 \%)$ & - \\
\hline Weakness & $2(14 \%)$ & $2(14 \%)$ & - & - & - \\
\hline Fever & $2(14 \%)$ & $2(14 \%)$ & - & - & - \\
\hline $\begin{array}{l}\text { Vision } \\
\text { problems }\end{array}$ & $1(7 \%)$ & $1(7 \%)$ & - & - & $1(7 \%)$ \\
\hline $\begin{array}{l}\text { Seasick-like } \\
\text { symptoms }\end{array}$ & $1(7 \%)$ & $1(7 \%)$ & $1(7 \%)$ & - & - \\
\hline
\end{tabular}

$H Z$ herpes zoster, $P H N$ postherpetic neuralgia

${ }^{\text {a }}$ Patients were asked about what led them to seek diagnosis, although they may have presented with additional symptoms prior to diagnosis

summarized in Table S1. Most participants were female $(72 \%)$, the average age was 61 years, almost all reported their ethnicity as white (94\%), and 50\% were married.

\section{Saturation}

New concepts were reported until the 15th interview for Group A and the 9th interview for Group B. No new concepts were reported in the final two interviews, indicating that saturation was reached in the sample.

\section{Patients' Descriptions of $\mathrm{HZ}$}

Figure 1 summarizes the most common descriptors reported by patients and presents some quotations to illustrate the patients' descriptions of their experiences. The most common words used by patients to describe their experience of $\mathrm{HZ}$ and PHN were 'pain' or 'painful,' reported by 24 (75\%) patients overall and by at least half in each group. Other descriptors reported by at least three patients each were 'burn' or 'burning,' 'debilitating,' 'surprising,' 'exhausting,' 'long-lasting,' 'itchiness,' 'frustrating,' 'scary,' 'interrupts sleep' and 'worry' (Fig. 1).

\section{Symptoms of HZ}

The disease-defining symptoms of rash and pain were reported by 32 patients and 31 patients, respectively (Table 1). These were also the most common symptoms reported as the reason for seeking diagnosis in both $\mathrm{HZ}$ and $\mathrm{PHN}$ patients 


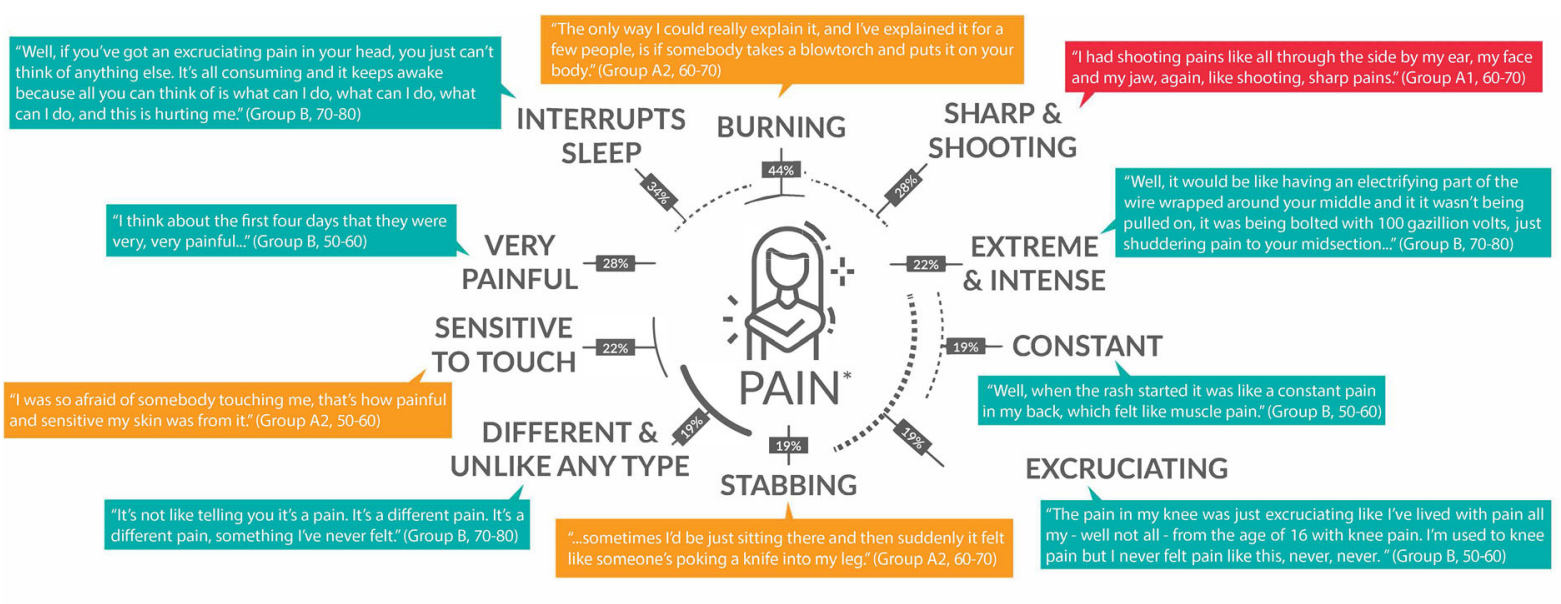

Fig. 2 Patient descriptions of pain. $F$ female, $H Z$ herpes zoster, $M$ male, $P H N$ postherpetic neuralgia. Group A1, HZ 7-30 days post diagnosis; Group A2, HZ 31-60 days post diagnosis; Group B, PHN; 50-60, patients between 50 and 59 years of age; $60-70$, patients between 60 and

(Table 1). Words and phrases used by patients to describe their HZ rash are presented in Fig. S4. The most commonly used descriptors were 'resembling insect bite' $(n=5)$, 'burning' $(n=5)$ and 'red' $(n=5)$. Pain was reported at the rash site for all except one patient. Descriptors used by patients in relation to their experience of pain are shown in Fig. 2. The most common words or phrases used by patients to describe the pain from shingles were burning pain $(n=14)$, interrupts sleep $(n=11)$, very painful $(n=9)$, sharp/shooting pain $(n=9)$, sensitive to touch $(n=7)$ and extreme/intense pain $(n=7)$. Patients described the intensity of the pain in vivid terms, comparing it to a blowtorch, a knife wound or an electric shock (Fig. 2). Of the 31 patients who reported pain, 10 spontaneously reported headaches, and three patients indicated that headache was their most bothersome pain symptom.

After rash and pain, the most commonly reported symptoms were fatigue and itchiness, reported by at least half of patients (Table 1). Most symptoms were spontaneously reported. Pain was rated as the 'most bothersome' symptom by $63-70 \%$ of patients. Itchiness was rated as the 'most bothersome' symptom by $20-25 \%$ of patients (Table 1).
69 years of age; 70-80, patients between 70 and 79 years of age. *Words and/or phrases reported by $<6$ patients not included

\section{Impact of $\mathrm{HZ}$ on Health-Related Quality of Life (HRQoL)}

Figure 3 presents patients' descriptions of the impact of HZ/PHN on their HRQoL. Table S2 shows the frequency of HRQoL impacts reported in $\mathrm{HZ}$ and $\mathrm{PHN}$ patients and provides quotations to illustrate the patients' descriptions of the HRQoL impact.

\section{Proximal Impacts}

Proximal impacts on HRQoL refer to effects that result directly from $\mathrm{HZ}$ symptoms, for example, impairment due to the rash site, sleep, physical functioning or activities of daily living. Impairment due to the rash site includes hearing loss from ear rash or visual problems from eye rash and was reported by one patient (Table S2). Effects on sleep were reported by 29 patients (Table S2). When asked why they had difficulty staying asleep, patients most frequently mentioned pain as the reason $(n=8)$, followed by itchiness $(n=3)$.

Effects on physical functioning were reported by 25 patients (Table S2). Physical activities were most commonly reported as limited 
because of difficulty with movement $(n=8)$, walking $(n=6)$ and exercise $(n=5)$. Four PHN patients reported impacts that lasted past the acute phase. Six patients described impacts on everyday physical functioning, 8 patients described impacts on moderate activity (such as walking short distances or using stairs), and 11 described impacts on strenuous activity such as running/walking long distances or playing sports.

Almost all patients $(n=31)$ reported impacts of HZ on activities of daily living (Table S2). Self-care was the most commonly reported activity of daily living affected by $\mathrm{HZ}$, reported by 31 patients. The most frequently mentioned areas of self-care that were affected were getting dressed $(n=11)$, grooming $(n=6)$ and bathing/ showering $(n=8)$. Other activities of daily living that were reported as affected by HZ included cooking $(n=9)$, errands $(n=5)$, walking $(n=5)$ and driving $(n=5)$.

\section{Distal Impacts}

Distal impacts on HRQoL refer to broader effects of $\mathrm{HZ}$ beyond the direct results of HZ symptoms, although there is likely to be a continuum between proximal and distal impacts with some overlap. Emotional functioning was the most commonly reported distal impact, reported by $31 / 32$ patients (Table S2). The most commonly reported emotional impacts were worry ( $n=16)$, feeling self-conscious/embarrassed $(n=11)$, feeling isolated $(n=11), \quad$ feeling drained $(n=9), \quad$ stress/anxiety $(n=9)$ and anger/frustration $(n=7)$.

Effects on hobbies and social functioning were also reported by more than half the patients ( $n=21$ and $n=20$, respectively) (Table S2). Examples of hobbies that patients reported as being affected by $\mathrm{HZ}$ included knitting, ice hockey, hand embroidery, going to church, motorcycle riding, bumper cars, art/painting, cooking/baking, running and dog walking. Hobbies were mostly self-described by the patients. The most frequently mentioned impact on social functioning was social isolation $(n=15)$, primarily to avoid infecting others or avoid pain from being touched by others.
Fig. 3 Patient descriptions of the impact of HZ/PHN on HRQoL. HRQoL health-related quality of life, $H Z$ herpes zoster, $P H N$ postherpetic neuralgia. Group A1, HZ 7-30 days post diagnosis; Group A2, HZ 31-60 days post diagnosis; Group B, PHN; 50-60, patients between 50 and 59 years of age; 60-70, patients between 60 and 69 years of age; $70-80$, patients between 70 and 79 years of age

Effects on work or career were reported by 12 patients (Table S2). Six patients reported that HZ had an impact on their ability to concentrate at work, and one patient described how this difficulty in concentrating also had an emotional effect. Work/career impacts were reported by one patient in Group A1 (HZ 7-30 days after diagnosis), four patients in Group A2 (HZ 31-60 days after diagnosis) and seven patients in Group B (PHN), indicating that impacts on work/career may be more likely the longer the disease episode lasts. However, all 11 patients who were asked about impacts on their long-term career goals said that $\mathrm{HZ}$ had no impact.

Effects on cognitive functioning and financial impacts were each reported by nine patients and effects on appetite and/or diet by five patients (Table S2).

\section{Changes in HRQoL Impacts over Time}

Impacts of HZ on HRQoL were more commonly reported for the acute phase of illness, and most patients reported that the impacts improved or resolved when the rash disappeared. However, some patients in the PHN group reported continuing impacts on activities of daily living, physical functioning, sleep and hobbies in the post-acute phase (Table S2).

\section{Domains of Quality of Life Affected}

Patients were asked to rank the five domains of quality of life that were most affected by $\mathrm{HZ}$ or PHN, and the results are summarized in Table S3. Pain was ranked as the most affected by nine participants, and six ranked social functioning as the most affected. Physical functioning was reported as the second most 


\section{Shingles}

\section{Impact on quality of life}
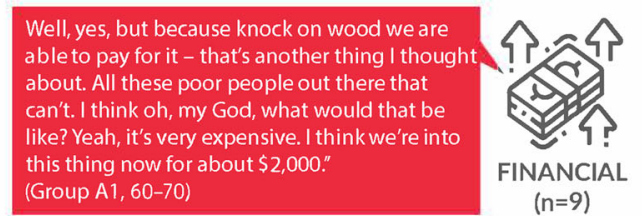

FINANCIAL

$(n=9)$

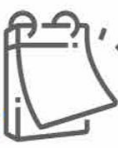

ACTIVITIES OF DAILY

LIVING

$(n=31)$

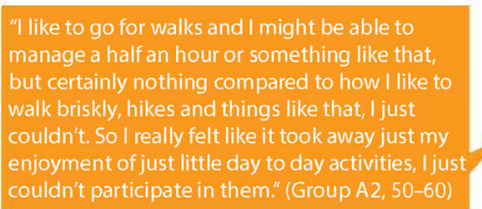

PHYSICAL:

$\begin{array}{r}(n=25) \\ \hline\end{array}$

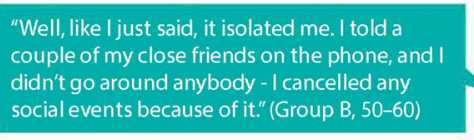

por

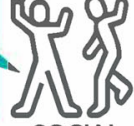

SOCIAL

FUNCTIONING

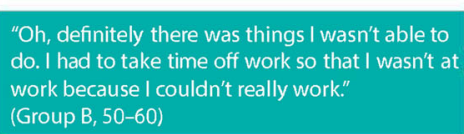

$(\mathrm{n}=20)$
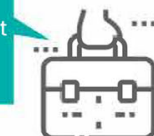

WORK \&

"I had some visual problems and it was, the rash

came out and was right down in through my

eye, my right eye, and then across to my ear."

(Group B, 70-80)

\section{CAREER}

( $n=12)$

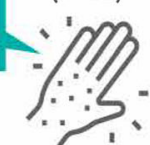

MPAIRMENT

DUE TO RASH SITE

$(n=1)$

Group A1: HZ patients interviewed 7-30 days post-diagnosis

Group A2: HZ patients interviewed 31-60 days post-diagnosis Group B: Post-herpetic neuralgia patients t did, yeah, it did affect my diet. Like I started

to eat way more junk food because l just - likel

said you just want to take it easy with every-

thing, so it's oh, yeah, that would taste good,

so... [laughs] A lot less self-disciplined. About

food, about everything." (Group A2, 60-70)

APPETITE

$\&$ DIET

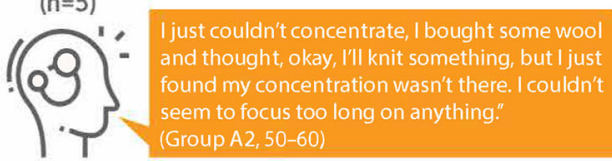

COGNITIVE

FUNCTIONING

$(\mathrm{n}=9)$

"Yes, I was frustrated and sad. You know, it was a

why me, you know, what did I do and how did I

get this? I mean, it brought me right to the vac-

cination every time. You know, there are more

the sadness that I didn't get that vaccination

because I would have avoided that pain. You

know where l'm going? That is it. Yeah, you feel all those feelings. I felt all those feelings."

EMOTIONAL (Group B, 70-80)

$(n=31)$

"No, I'm notgoing back to the gym. That was a - good hobby for me. I was doing it five times a week. They said every day, I used to check

myself, I would say go every day and I would average five times a week." (Group B, 50-60) HOBBIES ( $n=21)$

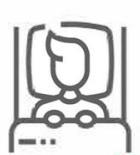

"I go down to sleep, and four hours. After four

hours, I wake up. I wake up, and it's very difficult

to go back to sleep. And then, what I need to do is get out of the bed, because it's better to get out of the bed, read, come to the living room

read, use the computer, do something, and then

after 2-3 hours after that activity at night, I go $(n=29)$

back to bed, and I can sleep again during the

morning another three hours. Which is terrible

for a person that could be working."

(Group B, 70-80) 
affected by eight patients, and four patients each selected pain, social functioning and emotional functioning as their second most affected domain.

\section{Final Conceptual Model}

Figure 4 shows the final conceptual model based on the results of the interviews, summarizing the most frequent symptoms of $\mathrm{HZ} / \mathrm{PHN}$ and the impacts on patients' HRQoL. A conceptual model provides a holistic, visual representation of all the important concepts related to patients' experience with a disease as well as the relationship between the concepts. This includes symptoms of the disease as well as proximal and distal impacts of the symptoms on functioning, activities of daily living and overall HRQoL.

\section{DISCUSSION}

This cross-sectional qualitative study used indepth interviews to explore individual subjective patient experiences of $\mathrm{HZ}$ and $\mathrm{PHN}$. To our knowledge, this is the first qualitative exploration of HRQoL impacts in $\mathrm{HZ}$ or PHN patients in Canada. This qualitative research complements previous quantitative studies using PRO measures such as the SF-36 and EQ-5D by providing a broader picture of patients' experiences

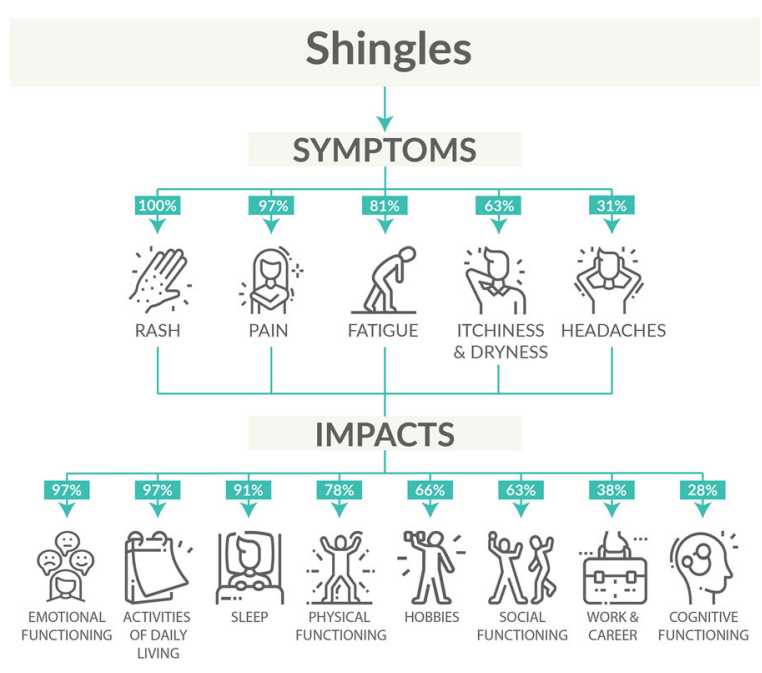

Fig. 4 Final conceptual model of HZ/PHN and the language they use to describe their experiences.

The core disease-defining symptoms of HZ/ PHN, rash and pain were reported by all patients and all except one patient, respectively. Pain severity reported in interviews was often very high, and some patients described their pain using vivid imagery such as a blowtorch, a knife wound or an electric shock. Our finding that patients chose to use this language to describe their pain illustrates the severity and intensity of their experiences. Itchiness and fatigue were also reported as symptoms by over half of patients.

Our results indicated that $\mathrm{HZ}$ and $\mathrm{PHN}$ have both proximal and distal impacts on a wide range of aspects of HRQoL. The broad range of impacts reported are consistent with a study conducted in Germany using telephone interviews with 280 patients with $\mathrm{HZ}$ or PHN, which reported that HZ/PHN caused substantial pain and negatively affected multiple domains of HRQoL [19]. Patients in our study described the pain and itchiness as interfering with sleep, consistent with other studies in which 55-65\% of patients reported not getting sufficient sleep $[19,20]$. Lack of sleep is important as it has far reaching consequences, e.g., neurobehavioral deficits such as lapses in attention, depression and cognitive impairment [21], and may also be associated with reduced work productivity, performance and safety [22]. Pain, rash and fatigue associated with $\mathrm{HZ}$ affected physical functioning and activities of daily living such as self-care and household tasks in our study. Schmader et al. [23] noted that the interference with activities of daily living was due primarily to the effects of HZ-related acute and chronic pain and discomfort, although the effects of the rash, eye involvement and neurological complications are also important. Our finding that some PHN patients reported HRQoL impacts in the post-acute phase of illness is consistent with a review of published evidence that reported that HRQoL could be permanently reduced even after the acute symptoms had resolved [6].

The patients' descriptions of their experiences of HZ/PHN indicate the complex interrelationships between symptoms and HRQoL impacts. Symptoms such as pain were 
mentioned as having multiple proximal and distal HRQoL impacts, affecting sleep, physical functioning, self-care, work, social interaction and emotional reactions (e.g., sadness that the pain could have been avoided by vaccination). Similarly, HRQoL impacts could be associated with multiple symptoms, for example, sleep was reported as affected by pain and itch, and patients described restrictions on physical activities related to pain, fatigue and rash. This suggests that the combined effects of several symptoms may interact to produce multifaceted HRQoL impacts of $\mathrm{HZ} / \mathrm{PHN}$, as represented visually in the final conceptual model. Outcome measures to assess HRQoL in HZ/PHN should consider symptoms beyond pain and should include a range of proximal and distal HRQoL impacts to present a full picture of the impact of the disease. The research presented here aims to give a voice to the patient and to help healthcare professionals gain a better understanding of patients' experience of $\mathrm{HZ} /$ PHN, including patients' frustration and the impacts on their daily lives. This in turn may help to support healthcare professionals in informing patients at risk of $\mathrm{HZ}$ of the potential value of preventive measures.

One of the strengths of the present study was the interview approach, which offers an enhanced understanding of the patient experience beyond that obtained from quantitative surveys. Another was the demographic composition of the sample, with a mean age of 61 years and a majority (72\%) of females, which is consistent with the higher incidence of $\mathrm{HZ}$ in women and at older ages $[24,25]$. Some limitations should also be noted. The ethnic diversity in the sample was minimal, which may limit the generalizability of the results. The study was conducted in a single country (Canada) and may not be generalizable to other countries. This was a cross-sectional study in which patients were interviewed at a single point in time in relation to their HZ/PHN episode, and therefore the study was not designed to follow changes over time. Interviewing patients at different time points after their initial diagnosis may have potential for recall bias. However, the inclusion of participants at a range of times after their $\mathrm{HZ}$ episode and of participants with PHN was intended to capture participants' subjective experiences of both acute and longer term impacts of illness. The recruitment process might have missed patients with more severe illness. There may be potential for bias related to any pre-conceived ideas held by the interviewer or self-reported patient bias if the patient tries to provide answers that they think the interviewer will want to hear. However, the use of trained interviewers and a semistructured interview guide should have helped to minimize these potential sources of bias.

\section{CONCLUSION}

In conclusion, this study shows that $\mathrm{HZ}$ and PHN had a negative impact on many dimensions of patients' HRQoL, particularly during the acute phase of illness. This qualitative study helps to broaden understanding of the impact of $\mathrm{HZ}$ on HRQoL from the patient's perspective. The conceptual model developed from the interview results may also help to guide further research. For example, it suggests that outcome measures to assess HRQoL in HZ/PHN should consider symptoms beyond pain and should include a range of proximal and distal HRQoL impacts. The conceptual model should help healthcare professionals to develop a broader understanding of the impact of $\mathrm{HZ} / \mathrm{PHN}$ on patients' lives.

\section{ACKNOWLEDGEMENTS}

The authors thank Michael Wortzman, Linda Nelsen, Rona Chen and Sarah Clifford for their input and review.

Funding. This work was funded by GlaxoSmithKline Biologicals S.A. (GSK study identifiers: HO-18-19396 and 209858), which was involved in all stages of the study conduct and analysis. GlaxoSmithKline Biologicals S.A. also funded all costs associated with the development and publishing of the present manuscript, including the journal's Rapid Service 
Fees. All authors had full access to the data and agreed with the submission of the publication.

Medical Writing, Editorial and Other Assistance. The authors also thank Business \& Decision Life Sciences platform for editorial assistance and manuscript coordination on behalf of GSK. Maxime Bessieres coordinated publication development and editorial support. Carole Nadin (Fleetwith Ltd, on behalf of GSK) provided writing support.

Prior Presentations. Interim results for three patients presented as a poster at EUGMS 2019, 25-27 September 2019, Krakow, Poland; abstract was presented at Canadian Public Health Association 2020 Annual Conference (CPHA 2020) in October 2020; abstract submitted to Canadian Geriatrics Society 40th Annual Scientific Meeting (CGS 2020), but this congress was cancelled and the abstract was published in the Canadian Geriatrics Journal.

Authorship. All named authors meet the International Committee of Medical Journal Editors (ICMJE) criteria for authorship for this article, take responsibility for the integrity of the work as a whole, and have given their approval for this version to be publish.

Author Contributions. Ashleigh McGirr, Desmond Curran, Desirée Van Oorschot, Philibert Goulet and Ramya Pratiwadi were involved in the conception and/or the design of the study. Desmond Curran, Desirée Van Oorschot, Philibert Goulet and Ramya Pratiwadi participated in the data collection/generation of the study data. All authors were involved in the interpretation of the data, reviewed and approved the final manuscript.

Disclosures. Desirée Van Oorschot, Ashleigh McGirr, Philibert Goulet and Desmond Curran are employed by and hold shares in the GSK group of companies. Patricia Koochaki, Ramya Pratiwadi and Selam Shah are salaried employees at ICON plc, which received funding from GSK to conduct the research. Philibert Goulet was affiliated with GSK at the time this study was carried out, and is currently affiliated with Incyte, Morges.

Compliance with Ethics Guidelines. All study materials were reviewed and approved by an independent ethics committee prior to patient recruitment (Advarra institutional review board [IRB], protocol number 0018-0873). All interviewers received studyspecific training on the interview guide and study protocol. At the start of the telephone interview, patients were asked to verbally confirm their informed consent and permission for the interview to be recorded and transcribed. Patients received honoraria of 150 Canadian Dollars (CAD) if they consented and took part in the interview, and an additional CAD25 for providing confirmation of diagnosis. Such patient honoraria are permitted in Canada and were reviewed and approved by the local IRB.

Data Availability. The datasets generated during and/or analyzed during the current study are available from the corresponding author on reasonable request.

Open Access. This article is licensed under a Creative Commons Attribution-NonCommercial 4.0 International License, which permits any non-commercial use, sharing, adaptation, distribution and reproduction in any medium or format, as long as you give appropriate credit to the original author(s) and the source, provide a link to the Creative Commons licence, and indicate if changes were made. The images or other third party material in this article are included in the article's Creative Commons licence, unless indicated otherwise in a credit line to the material. If material is not included in the article's Creative Commons licence and your intended use is not permitted by statutory regulation or exceeds the permitted use, you will need to obtain permission directly from the copyright holder. To view a copy of this licence, visit http://creativecommons.org/licenses/by$\mathrm{nc} / 4.0 /$. 


\section{REFERENCES}

1. Harpaz R, Ortega-Sanchez IR, Seward JF. Prevention of herpes zoster: recommendations of the Advisory Committee on Immunization Practices (ACIP) MMWR Recomm Rep. 2008;57(5):1-30, https:// www.cdc.gov/mmwr/preview/mmwrhtml/ rr5705a1.htm.

2. Centers for Disease Control and Prevention. About Shingles. https://www.cdc.gov/shingles/about/ index.html. Accessed $11 \mathrm{Jul} 2020$.

3. Brisson M, Edmunds WJ, Law B, et al. Epidemiology of varicella zoster virus infection in Canada and the United Kingdom. Epidemiol Infect. 2001;127(2): 305-14. s0950268801005921. https://doi.org/10.1017/

4. Brisson M, Pellissier JM, Camden S, Quach C, De Wals P. The potential cost-effectiveness of vaccination against herpes zoster and post-herpetic neuralgia. Hum Vaccin. 2008;4(3):238-45. https:// doi.org/10.4161/hv.4.3.5686.

5. Government of Canada. Herpes Zoster (Shingles) Vaccine: Canadian immunization guide. https:// www.canada.ca/en/public-health/services/ publications/healthy-living/canadianimmunization-guide-part-4-active-vaccines/page-8herpes-zoster-(shingles)-vaccine.html\#a2. Accessed $11 \mathrm{Jul} 2020$.

6. Johnson RW, Bouhassira D, Kassianos G, Leplege A, Schmader KE, Weinke T. The impact of herpes zoster and post-herpetic neuralgia on quality-oflife. BMC Med. 2010;8:37. https://doi.org/10.1186/ 1741-7015-8-37.

7. Chidiac C, Bruxelle J, Daures JP, et al. Characteristics of patients with herpes zoster on presentation to practitioners in France. Clin Infect Dis. 2001;33(1):62-9. https://doi.org/10.1086/320884.

8. Curran D, Schmidt-Ott R, Schutter U, Simon J, Anastassopoulou A, Matthews S. Impact of herpes zoster and postherpetic neuralgia on the quality of life of Germans aged 50 or above. BMC Infect Dis. 2018;18(1):496. https://doi.org/10.1186/s12879. 018-3395-z.

9. Katz J, Cooper EM, Walther RR, Sweeney EW, Dworkin RH. Acute pain in herpes zoster and its impact on health-related quality of life. Clin Infect Dis. 2004;39(3):342-8. https://doi.org/10.1086/ 421942.

10. Schmader KE, Sloane R, Pieper C, et al. The impact of acute herpes zoster pain and discomfort on functional status and quality of life in older adults.
Clin J Pain. 2007;23(6):490-6. https://doi.org/10. 1097/AJP.0b013e318065b6c9.

11. Gater A, Nelsen L, Fleming S, et al. Assessing asthma symptoms in adolescents and adults: qualitative research supporting development of the asthma daily symptom diary. Value Health. 2016;19(4): 440-50. https://doi.org/10.1016/j.jval.2016.01.007.

12. McCarrier KP, Bull S, Fleming S, et al. Concept elicitation within patient-powered research networks: a feasibility study in chronic lymphocytic leukemia. Value Health. 2016;19(1):42-52. https:// doi.org/10.1016/j.jval.2015.10.013.

13. Turner-Bowker DM, Lamoureux RE, Stokes J, et al. Informing a priori sample size estimation in qualitative concept elicitation interview studies for clinical outcome assessment instrument development. Value Health. 2018;21(7):839-42. https:// doi.org/10.1016/j.jval.2017.11.014.

14. Grant L, Seiding Larsen L, Trennery C, et al. Conceptual model to illustrate the symptom experience and humanistic burden associated with atopic dermatitis in adults and adolescents. Dermatitis. 2019;30(4):247-54. https://doi.org/10.1097/DER. 0000000000000486 .

15. Corbin JM, Strauss A. Basics of qualitative research: techniques and procedures for developing grounded theory. 4th ed. Thousand Oaks: SAGE Publications, Inc; 2015.

16. Glaser B, Strauss A. The discovery of grounded theory. London: Weidenfeld and Nicholson; 1967.

17. Joffe H, Yardley L. Content and thematic analysis. In: Marks DF, Yardley L, editors. Research methods for clinical and health psychology. London: Sage Publications; 2004. p. 56-67.

18. Kelle U. 'Emergence' vs 'forcing' of empirical data 7 a crucial problem of 'grounded theory' reconsidered. Forum 2005;6(2), http://www.qualitativeresearch.net/index.php/fqs/article/view/467/1000.

19. Weinke T, Edte A, Schmitt S, Lukas K. Impact of herpes zoster and post-herpetic neuralgia on patients' quality of life: a patient-reported outcomes survey. Z Gesundh Wiss. 2010;18(4):367-74. https://doi.org/10.1007/s10389-010-0323-0.

20. Lukas K, Edte A, Bertrand I. The impact of herpes zoster and post-herpetic neuralgia on quality of life: patient-reported outcomes in six European countries. Z Gesundh Wiss. 2012;20(4):441-51. https:// doi.org/10.1007/s10389-011-0481-8.

21. Banks S, Dinges DF. Behavioral and physiological consequences of sleep restriction. J Clin Sleep Med. 
2007;3(5):519-28, https://www.ncbi.nlm.nih.gov/ pubmed/17803017.

22. Rosekind MR, Gregory KB, Mallis MM, Brandt SL, Seal B, Lerner D. The cost of poor sleep: workplace productivity loss and associated costs. J Occup Environ Med. 2010;52(1):91-8. https://doi.org/10. 1097/JOM.0b013e3181c78c30.

23. Schmader KE, Johnson GR, Saddier P, et al. Effect of a zoster vaccine on herpes zoster-related interference with functional status and health-related quality-of-life measures in older adults. J Am Geriatr Soc. 2010;58(9):1634-41. https://doi.org/10.1111/j. 1532-5415.2010.03021.x.

24. Johnson BH, Palmer L, Gatwood J, Lenhart G, Kawai K, Acosta CJ. Annual incidence rates of herpes zoster among an immunocompetent population in the United States. BMC Infect Dis. 2015;15:502. https://doi.org/10.1186/s12879-0151262-8.

25. Kawai K, Gebremeskel BG, Acosta CJ. Systematic review of incidence and complications of herpes zoster: towards a global perspective. BMJ Open. 2014;4(6): e004833. bmjopen-2014-004833.

https://doi.org/10.1136/

\section{Publisher's Note}

Springer Nature remains neutral with regard to jurisdictional claims in published maps and institutional affiliations. 